Arctic, under the leadership of Dr. Noel Humphreys. The plans of the Expedition are to leave London in July in a sealer chartered from Norway and to winter in Ellesmere Land, next spring being devoted to an exploration of Northern Ellesmere Land. The interior is unexplored and a geological survey of this country will be the chief scientific work undertaken. The Expedition is financed partly by its members and partly by scientific societies and individual sub. scribers. The greater part of the food supply has been obtained free owing to the generosity of a number of firms. The Expedition will consist of five or six members, but a geologist is still urgently required. Besides being physically fit and prepared to be away from England for a year, he should have had some field experience. Communications referring to the Expedition should be addressed to Mr. E. A. A. Shackleton, Oxford University Ellesmere Land Expedition, 1934, Royal Geographical Society, London, S.W.7.

\section{Archæological Exploration in Alaska}

Dr. Aueš Hrduička, accompanied by a number of volunteer students, left Washington on May 11 for a further season's work on Kodiak Island, Alaska. Several seasons have already been devoted by Smithsonian expeditions, of which Dr. Hrdlička has been in charge, to the examination of sites on this island. The results have shown that it was at one time thickly populated and was in all probability a stepping stone in the peopling of America by migrants from Asia. The earliest inhabitants, whose skeletal remains have been found at the bottom of the accumulated debris, represent the earliest remains of man which have been found in the far north. They are not, however, ancient in the geological sense. In type they approach the physical characters of the Indians of California and the west coast. The earliest immigrants introduced a high order of stone culture, and many of the objects found with them are unique. They were succeeded by the Aleut, who were the inhabitants at the time of the coming of the Russians. A remarkable feature in the culture of the older population is that it is not identical throughout. A marked change takes place in the course of their period of occupation. In the coming season, work will be confined to one large village, already partially explored. The site will be subjected to intensive study in the hope of obtaining a decisive answer to some, at least, of the problems which have been raised in the investigations of previous years.

\section{International Eugenics Conference}

THE biennial conference of the International Federation of Eugenic Organisations will take place at Zurich on July 18-21 under the presidency of Prof. Ernst Rüdin of Munich. A programme has been arranged providing for the discussion of subjects of immediate interest in which eminent specialists have been invited to take part. Addresses will be delivered by, among others, Prof. Rüdin on "Racial Psychiatry - a Scheme for Topographical Research in Europe", Dr. Mjoer on "Measurement of Psycho- logical Faculty as shown in Musical Ability", and Prof. Von Verschuer on "Researches in Twins". Dr. Rüdin will also explain the provisions of the recent German eugenics law; and it is hoped that one of the public health officers of the Reich will give an address on the questionnaire now used in Germany for assessing intelligence grade. Among the subjects down for discussion are the assessment of feeble-mindedness-to be held in a joint session of the Committee for Racial Psychiatry and Section $\mathrm{B}$ of the International Committee for the Standardisation of Human Measurement mental measurement and its relation to diagnosis of temperamental type, aspects of the problems of differences between, and inheritance in, monozygotic and dizygotic twins, and the best methods of conducting a central clear. ing house for human heredity, this last-named including the questions of the establishment of national bureaux, and the protection of authors whose material is published. The work of the Standardisation Committee in Anthropometry will be continued at the International Congress of Anthropological Sciences to be held in London at the end of July.

\section{Prof. Erwin Baur}

HeFT 17-18 of Die Naturwissenschaften, which appeared on April 27, is devoted to the memory of Erwin Baur, who died in December last. A short general account by Dr. Max Hartmann of his work and its significance in leading to a general appreciation of genetics in Germany is followed by a series of twelve articles written by colleagues of Baur whom he trained in the institute of which he was head, outlining in more detail the results achieved by the institute for plant breeding which he founded at Müncheberg. Five papers dealing with his theoretical work discuss respectively his investigations of mutation, linkage, specific crossing and self-sterility in Antirrhinum, and his genetical work on Pelargonium and Cleome. In seven other papers are considered the practical plant-breeding results obtained with rye, wheat, barley, sweet lupins, fodder plants, potatoes and grapes. Further papers on the practical results will appear in later numbers of the same journal. An obituary notice of Prof. Baur appeared in Nature of February 17.

\section{Barter in Great Britain}

IN the United States, the direct barter of goods and services has developed rapidly since 1931 as a practical method of alleviating unemployment and social distress. So far, little appears to have been done in Great Britain along similar lines, possibly because social insurance is highly developed, whereas in the United States it is practically non-existent. It is of interest therefore to note that, according to Progress and the Scientific Worker, experimental barter schemes have been inaugurated near Cheltenham and Petersfield. The Cheltenham scheme was started under the leadership of Prof. Scott of University College, Cardiff. Four acres of land were purchased 
to be cultivated co-operatively by a group of men. They receive no remuneration for their work other than coupons signed by Prof. Scott according to the time spent on work. These coupons are equivalent in value to half a pound of potatoes, and can also be exchanged for knitted socks made by a member or for boot repairs undertaken by another member. Later on, it is hoped to extend the variety of goods and services obtainable for the coupons. At Petersfield the system is further developed and the work undertaken by various members includes cultivation of allotments, poultry farming, wood cutting, cobbling, carpentry and general repairs. To break up the land, a tractor has been borrowed from a local firm. The commodities or services are exchanged among the members while surplus farm produce is sent to an occupation centre in exchange for surplus clothes made in the centre.

\section{Gutta Percha, Balata and Caoutchouc}

Prof. G. G. Henderson, in delivering the twentysixth Bedson Lecture in Newcastle-upon-Tyne on May 18, outlined the work carried out in his laboratories on the subjects of gutta percha, balata and caoutchouc. The peculiar difficulties of the subjectwhich he advised research workers to avoid-are the lack of criteria of purity, complete absence of crystalline compounds, ready resinification at tem. peratures above $40^{\circ}$, and attack by air. Oxidation experiments with hydrogen peroxide yielded alcoholic substances in each case, which when treated. successively with acetic anhydride, further peroxide and aqueous barium hydroxide gave, from each source, so far as could be determined, the same final alcoholic product. Hydrogenation with a palladium catalyst gave results in agreement with the general formulæ $\left(\mathrm{C}_{5} \mathrm{H}_{8}\right)_{x} \rightarrow\left(\mathrm{C}_{5} \mathrm{H}_{10}\right)_{x}$ with the anticipated increase in stability. This is in agreement with the general conception of chains of isoprene units linked head to tail with loss of one double bond per unit. The hydrochlorides of these substances on treatment with metallic zinc gave, not the same dihydrides, but quite different substances with the original empirical formula but one unsaturated linkage to each two isoprene units, which may be due to cyclisation on loss of hydrogen chloride. Finally, the dibromo addition compounds condensed with phenols in the presence of anhydrous ferric chloride to yield coloured substances with the properties of indicators, one being very suitable for the titration of halides with silver nitrate.

\section{Marine Electrification}

SEvErat important developments in connexion with marine electrification are described in the G.E.C. Journal of February. In the past, fishing trawlers have been illuminated by means of carbide lamps which, apart from their disadvantages from an illuminating point of view, introduce a serious fire risk. Special equipment has now been designed and installed on one of the trawlers of a Scottish fishing fleet which enables electric lighting to be used. The installation has been very successful and the practice of electrically floodlighting the decks of trawlers will be widely used. The Company also completed the electrical propulsion equipment of the Diesel-electric tug, Acklam Cross. This is the first British vessel of her type, the first to have high-speed Diesel prime movers, the first to have a clear after deck, and the first to have an electrical system of starting the prime movers. The system adopted seems admirably suited to fulfil all the special requirements of a tug. It is capable of going on duty at a moment's notice. It is also capable of rapid manœuvring when towing large vessels in and out of congested harbours. There is practically no delay in exerting full power ahead or astern. The Dieselelectric engine can be started up as quickly as a motor-car engine and during periods of inactivity no fuel at all is consumed. The control of the speed and the direction of the controller is directly in the hands of the navigating officer. Starting is effected immediately by pressing a button. The mean speed over the measured mile was $11 \cdot 15$ knots. The time taken from rest to full speed ahead was 24 seconds and from stop to full astern was 16 seconds. The electro-hydraulic steering gear was very efficient, the vessel being capable of turning at full speed in under two lengths.

\section{Research Activities of the Mellon Institute}

THE twenty-first annual report of the Director of the Mellon Institute, covering the year 1933-34, directs attention to the improvement in the position of research during recent months and illustrates the wide range of industries which benefit from the activities of the Institute. Sixty-six industrial fellowships were in operation during the year, requiring the services of 101 fellows and 34 assistants, and fifty-five fellowships were in operation at the end of the year. Fellows and assistants then numbered 104 as against 98 in the previous year ; new fellowships commencing operations during the year dealt with cosmetics, nitrogen compounds, calgonising, rayon, new plastics, phosphates, tar acids, textile finishing, etc. The calgonising fellowship is concerned with the properties and utility of sodium meta. phosphate ('calgon') in textile and laundry technology, the fellowship on phosphates is occupied with their pharmacology and therapeutic value, and a fellowship to investigate problems in starch technology has recently been accepted. The discovery of a process for flaking coffee by the application of high pressure to ground freshly roasted coffee made in a study of the packing of coffee is claimed as an important technical and practical advance. Other investigations have led to the marketing of new and improved strained foods. Industrial applications of the newer organic solvents have been assisted and a new water-soluble lubricant has been introduced for worsteds and wool. New plasticisers, new types of resins, adhesives which do not cause discoloration of envelopes on sealing, the synthesis of new types of amines, are among other achievements of the Institute, which can also point to important investigations on steel, the development of novel building materials, studies on heat insulation and efforts at smoke abatement as other evidence of its importance 